1 Manuscript was completed on the $21^{\text {st }}$ of April 2020.

2 Discussion on the separation of macropores and micropores in a compacted expansive clay

3 Shengyang Yuan ${ }^{1}$, Xianfeng Liu ${ }^{2}$, Enrique Romero $^{3}$, Pierre Delage $^{4}$, Olivier Buzzi $^{5}$

\title{
4 Affiliations:
}

$5 \quad{ }^{1,2}$ Key Laboratory of High-speed Railway Engineering of Ministry of Education, School of

6 Civil Engineering, Southwest Jiaotong University, Chengdu 610031, China.

$7 \quad$ 1,2,5 Priority Research Centre for Geotechnical Science and Engineering, The University of 8 Newcastle, University of drive, Callaghan, NSW, 2308, Australia.

$9{ }^{3}$ Department of Geotechnical Engineering and Geosciences, Universitat Politècnica de 10 Catalunya, Barcelona Spain.

$11{ }^{4}$ Ecole des Ponts ParisTech, 6-8 av. Blaise Pascal, Cité Descartes, Champs-sur-Marne, F1277455 MARNE LA VALLEE, France.

$13{ }^{1}$ Associate Professor, Email: shengyang.yuan@swjtu.edu.cn

$14 \quad 2$ Professor, Email: Xianfeng.liu@swjtu.edu.cn

15 3Professor, Email: enrique.romero-morales@upc.edu

$16{ }^{4}$ Professor, Email: pierre.delage@enpc.fr

17 5Professor, Email: olivier.buzzi@newcastle.edu.au

19 Corresponding author: Dr. Xianfeng Liu,_Xianfeng.liu@swjtu.edu.cn

20 Main text contains 2119 words

216 Figures, 3 Tables. 
Abstract:

The behaviour of clayey soils is strongly correlated to their microstructure and evolution thereof. Microstructural investigations have contributed to understanding soil behaviour and have supported the development of multi-scale coupled models. One of the most accessible methods to characterize soil microstructure is mercury intrusion porosimetry, which provides a pore size distribution (PSD) ranging from few nanometers to several hundreds of micrometers. PSDs can be used to compute micro and macro strains or simply to estimate, in aggregate microstructures, the void ratios associated to macro pores and micro pores. However, in both cases, a boundary has to be set to separate the different pore populations. This paper discusses some criteria that have been proposed in the literature to separate the pore populations. The discussion is illustrated with extensive micro structural data obtained for Maryland clay. The paper highlights the effect of initial conditions and boundary conditions on the delimiting diameter given by some of the criteria. It is also shown that using different criteria will yield different values of delimiting pore size, with a risk of obtaining unrealistic estimates of micro and macro void ratios and strains. Finally, it is suggested to account for known soil behaviour to interpret microstructural data.

List of notations: not applicable.

Key words: expansive soils, swelling, microstructure, MIP, SEM, micropores, macropores

\section{1- Introduction}

A remarkable number of studies have investigated the microstructure of clayey soils and its evolution under wetting, drying, aging or changes in effective stress (Diamond, 1970; Sridharan et al., 1971; Ahmed et al., 1974; Delage and Lefebvre 1984; Griffith and Joshi 1989, Simms and Yanful, 2001; Agus and Schanz, 2005; Delage et al., 2006; Koliji et al., 2006; Thom et al., 2007; Li and Zhang, 2009; Romero, 2013). Mercury intrusion prorosimetry (MIP) is commonly used for microstructural analysis of dehydrated soils (often by freeze-drying, Zimmie and Almaleh, 1976; Delage and Pellerin, 1984; Yuan et al., 2018) because of the large range of pore size covered (3.5 nm to $0.4 \mathrm{~mm}$ ). Raw MIP data consists of the evolution of cumulative volume of intruded mercury per gram of specimen with mercury injection pressure, which is turned into an entrance pore diameter using Laplace-Young's equation. Multiplying the cumulative volume of intruded mercury per gram of soil by the unit mass of soil solid 
particles result in the intruded void ratio, here note $\mathrm{e}_{\mathrm{MIP}}$. The first derivative of intruded void ratio with respect to logarithm of entrance pore diameter corresponds to the pore size density function of sample. Its relative ease of use and the fact that it provides an overall pore size distribution of the specimen, rather than some local surficial information (Romero and Simms, 2009).

In parallel to experimental studies, a number of models have been developed (e.g. Alonso et al., 1999; Yong, 1999; Simms and Yanful, 2002; 2005; Sanchez et al., 2005; Romero et al., 2011; Casini et al., 2012; 2013; Della Vecchia et al., 2013; Masin, 2016) to account for couplings between macropores and micropores. However, distinguish micropores and macroopres is not always straightforward and different criteria have been adopted by various authors.

The literature contains little information on the variability of answers given by the different criteria, the effect of selecting one criterion over another and the parameters that can affect the selection of a criterion.

In this paper, five different criteria are applied to microstructural data recently obtained on Maryland Clay (Burton et al., 2015; Yuan et al., 2016; 2019a; 2020) in order to discuss the variability of delimiting diameter obtained and the effect of initial and boundary conditions on some criteria. Observations are made to guide researchers to decide on how to select an appropriate delimiting diameter. Very importantly, the separation between pores should not be considered solely in terms of pore size but, rather, from behavioural features, related to water adsorption or volume change, for example. 


\section{2- Material and experimental data}

The different criteria are discussed using MIP data obtained on compacted Maryland clay (Burton et al., 2015; Yuan et al., 2016; 2019a; 2020), a residual expansive clay containing about $10 \%$ in mass of interlayered illite-smectite clay (Liu et al., 2016; Yuan et al., 2016). It has a liquid limit around $70 \%$, a plastic limit around $25 \%$ and an optimum moisture content (under standard proctor compaction) around $24 \%$ for an optimum dry unit weight of 14.7 $\mathrm{kN} / \mathrm{m}^{3}$.

\section{3- Application of different criteria to Maryland Clay}

Five delimiting criteria are introduced below and applied to compacted Maryland clay (See Figure 1 and Table 2):

- The "VALL" criterion (Figure 1a) consists of using the lowest point of the valley between the two peaks of a bimodal pore size distribution (PSD).

- The "CNC" criterion (Figure 1b) was proposed by Delage and Lefebvre (1984). It is based on the concept of constricted and non-constricted porosity, identified from mercury intrusion and extrusion curves.

- The "RFS" and "RCV" criteria (Figure 1c), proposed by Romero et al. (2011), stem from the observation that, upon saturation, macro pores and micro pores merge into a monomodal distribution. The boundary between micro and macro is taken at the peak of the merged distribution. This approach applies to swelling under constant volume (RCV) and under free swell (RFS).

- The "SWRC" criterion, proposed by Romero et al. (1999), is based on the dependence of retention curves on void ratio. A delimiting diameter can be inferred by using Laplace's equation at the value of suction corresponding to the point of convergence of retention curves.

The RCV, RFS and SWRC criteria are derived from the physical response of soils and rely on specific tests:

- Criteria RFS and RCV require MIP data on specimens having swollen under no applied stress (free swell) and under constant volume, respectively.

- Criterion SWRC requires at least two retention curves (at constant void ratio) in order to identify the suction at which the two curves merge. 
These three criteria yield a "fixed" value of delimiting diameter that can then be used on other PSDs. In contrast, VALL and CNC criteria directly reflect pore geometry and can be applied to any PSD. As such, these values are considered as "moving" delimiting diameters.
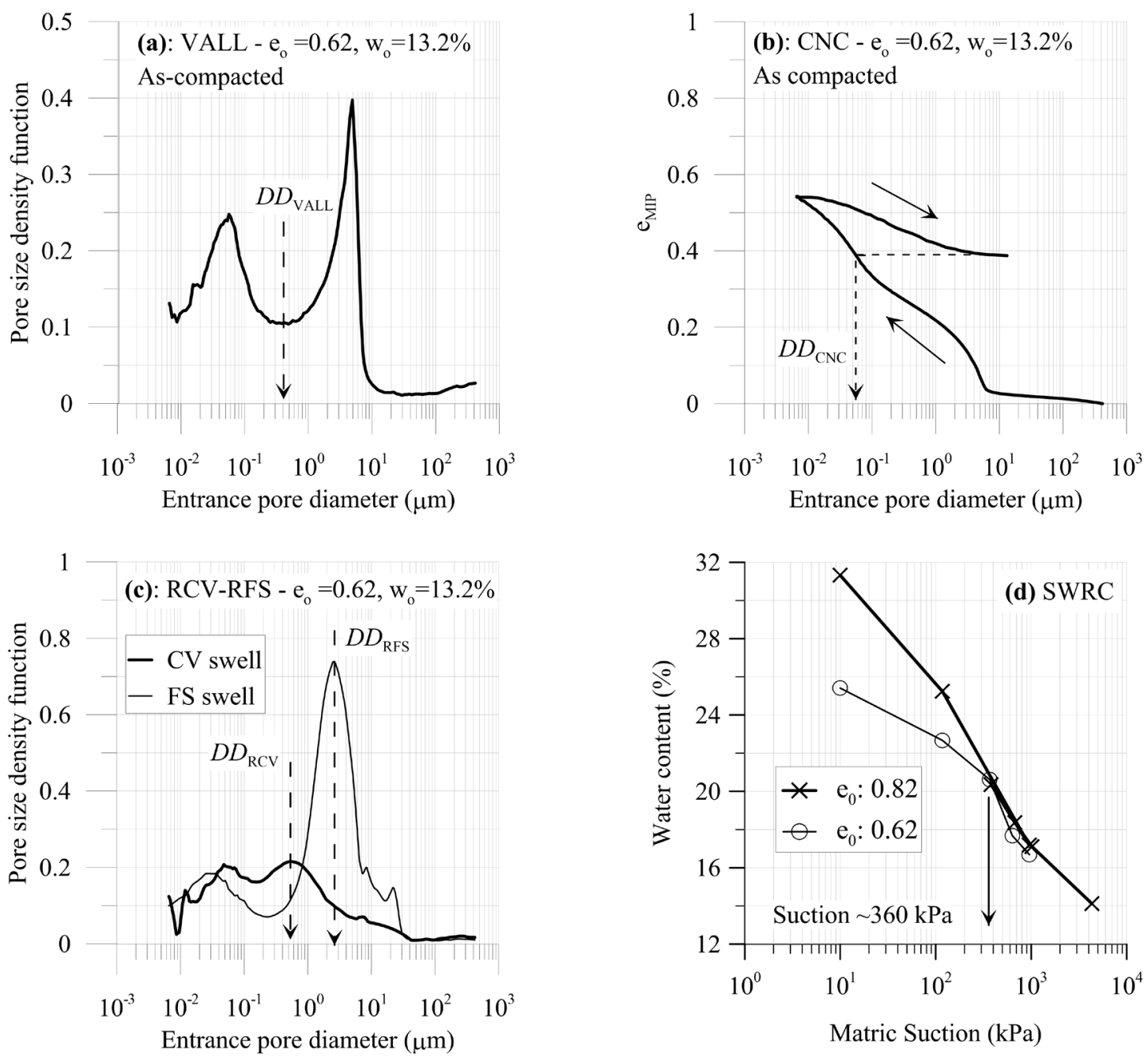

Figure 1: Criteria used to distinguish micropores and macropores, applied to pore size distribution (a-c) and retention curves (d) of Maryland clay. The pore size distributions pertain to compacted material or specimen after swelling. Information is provided, for each figure, in the legend. (a): VALL criterion, (b): CNC criterion, (c) RCV-RFS criteria, (d): SWRC criterion. Data from Yuan et al. (2016, 2019a, 2020). In the case of the VALL criterion, the midpoint is considered as the delimiting diameter $(D D)$ if there is a whole zone of similar low values.

The five criteria were applied to Maryland clay compacted at different values of void ratios and gravimetric water content. For the sake of conciseness, the values of delimiting diameter are presented only for one initial condition in Table 2. It can be seen that, depending on the criterion selected, the delimiting diameter ranges from 0.06 to $2.5 \mu \mathrm{m}$, with associated micro 
void ratios $\left(\mathrm{e}_{\mathrm{m}}\right)$ ranging from 0.22 to 0.46 . Consistent with Monroy et al. (2010), the CNC criterion yields a value of $0.06 \mu \mathrm{m}$, which is much lower than all other criteria and which almost coincides with the left peak of micropores in Figure 1a. As such, we here consider that it is not an adequate boundary and will not be discussed further in the rest of the paper.

Table 2: Summary of delimiting diameters for compacted Maryland clay (initial conditions of $e_{o}=0.62, w_{o}=13.2 \%$ ) and values of micro void ratio $\mathrm{e}_{\mathrm{m}}$, estimated from the PSD of the compacted soil using the delimiting diameters of each criterion.

\begin{tabular}{|c|c|c|c|c|c|}
\hline Criterion to define delimiting diameter & VALL & CNC & RCV & RFS & SWRC* \\
\hline Delimiting diameter $(\mu \mathrm{m})$. & 0.40 & 0.06 & 0.60 & 2.5 & 0.8 \\
\hline Micro void ratio $\mathrm{e}_{\mathrm{m}}$ & 0.36 & 0.22 & 0.38 & 0.46 & 0.39 \\
\hline
\end{tabular}

*: calculated using Laplace's equation with a suction of $360 \mathrm{kPa}$, a water surface tension of $72.5 \mathrm{mN} / \mathrm{m}$ (at 20 degrees ) and a contact angle of 0 degree.

\section{4- Significance of boundary conditions and initial conditions for "fixed value" criteria.}

The SWRC criterion relies on experimental retention curves determined at constant void ratio and, as such, boundary conditions and initial water content do not really apply. However, using a wetting branch or a drying branch to identify the merging point may affect the value of micro/macro boundary returned by the SWRC criterion. This effect was not verified with Maryland clay because the research conducted by Yuan et al. (2016, 2019a, 2019b, 2020) focused on wetting paths and swelling.

Yuan et al. (2019a) tracked the evolution of microstructural changes in compacted Maryland clay during wetting. Figure 2 shows the progressive merging of the two pore populations, for free swelling and hydration under constant volume. It can be seen, in Figure $2 \mathrm{a}$ and $2 \mathrm{~b}$, that merging is not complete and that some of the original micropores (pore size from $10^{-2} \mu \mathrm{m}$ to $\left.10^{-1} \mu \mathrm{m}\right)$ are still present in both distributions, even after full hydration.

Consequently, without progressive tracking of microstructural changes, the final PSD could be interpreted as having two pore populations. i.e. micropores with pore size between $10^{-2} \mu \mathrm{m}$ to $10^{-1} \mu \mathrm{m}$ and macro pores with pore size between $2 \cdot 10^{-1} \mu \mathrm{m}$ to $10 \mu \mathrm{m}$. 
142 Using the RFS criterion on the PSD of the fully hydrated specimen (Figure 2a) returns a micro 143 void ratio around 0.38 . In contrast, considering a limit between 0.1 and 0.2 micrometer (VALL 144 criterion), assuming that the micropores only correspond to the left peak, returns an $\mathrm{e}_{\mathrm{m}}$ value 145 in the order of 0.1 , i.e. four times less.

146 For Boom clay, Romero et al. (2011) concluded that the boundary conditions did not affect the 147 position of the dominant peak post-swelling. However, this is clearly not the case for Maryland 148 clay (see Figure 2) and the difference in peak position is quite significant: $2.5 \mu \mathrm{m}$ for free swell against $0.6 \mu \mathrm{m}$ for constant volume.

150 Figure 3 provides further evidence that, for Maryland clay, the position of the merged peak 151 depends on boundary conditions (Figures 3a and 3b) and initial conditions (Figure 3c) applied 152 during swelling.

153 As expected, increasing the vertical stress on a specimen shifts the merged mono-modal peak 154 post swelling towards smaller pore size. The effect is more pronounced for the combination of 155 intial void ratio and initial water content that would result in most swelling, i.e. $e_{0}=0.62$ and $\mathrm{W}_{\mathrm{o}}=13.2 \%$ (swelling pressure in excess of $400 \mathrm{kPa}$, Yuan et al. 2016). This is because the soil compacted at $\mathrm{e}_{\mathrm{o}}=0.82$ and $\mathrm{w}_{\mathrm{o}}=17.8 \%$ develops less swelling pressure (around $100 \mathrm{kPa}$, Yuan et al., 2016) under constant volume condition, resulting in less aggregate re-arrangement.

159 Table 3 summarizes the values of delimiting diameters obtained from the RCV, RFS and 160 SWRC criteria for four different initial conditions for Maryland clay. 


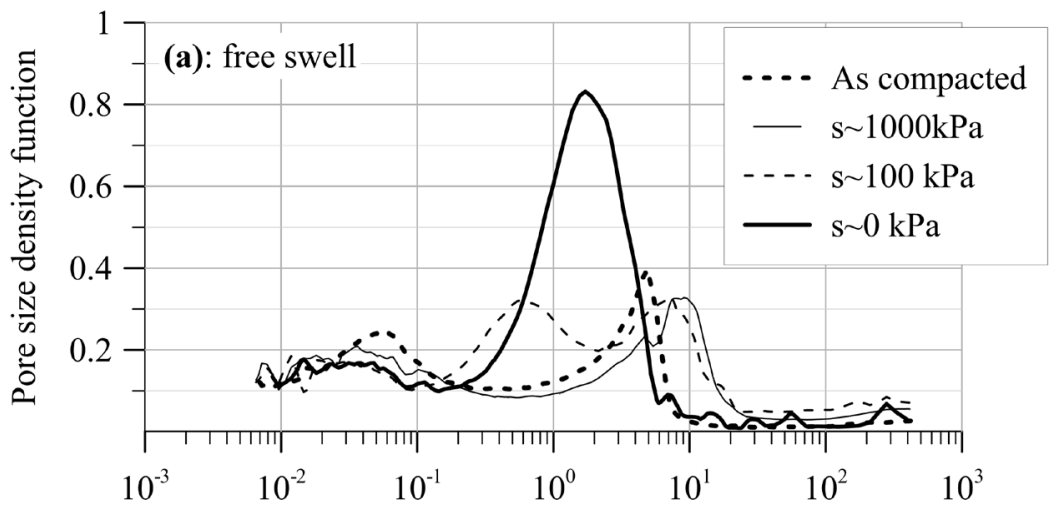

Entrance pore diameter $(\mu \mathrm{m})$

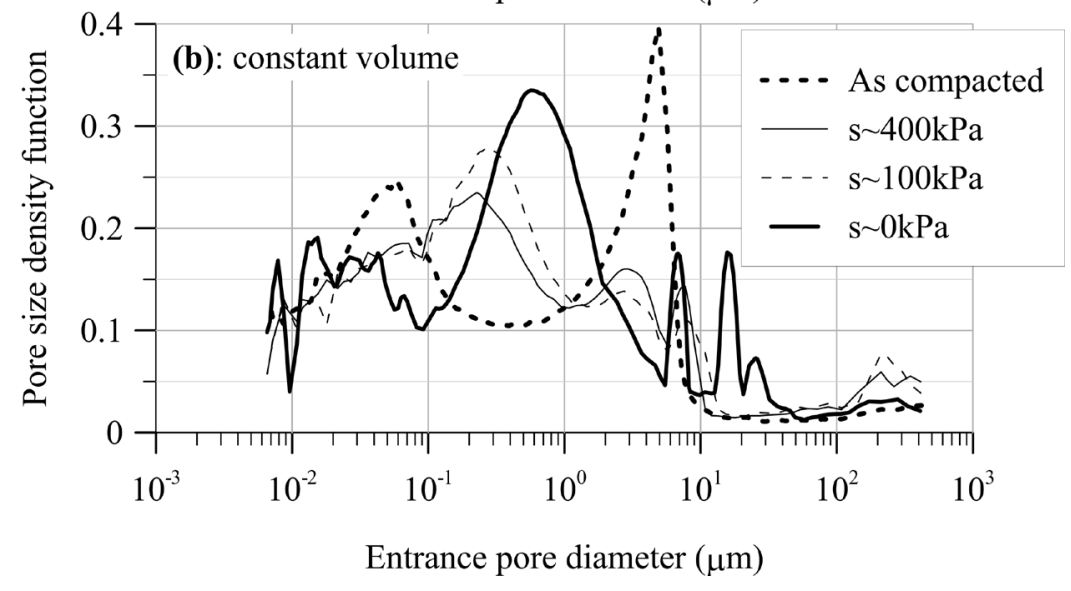

Figure 2: evolution of pore size distribution during free swelling (a) and swelling under constant volume (b). The specimen was initially compacted at $\mathrm{e}_{0}=0.62$ and $\mathrm{w}_{0}=13.2 \%$. Suction was incrementally reduced using the osmotic method. Data from Yuan et al. (2019). 

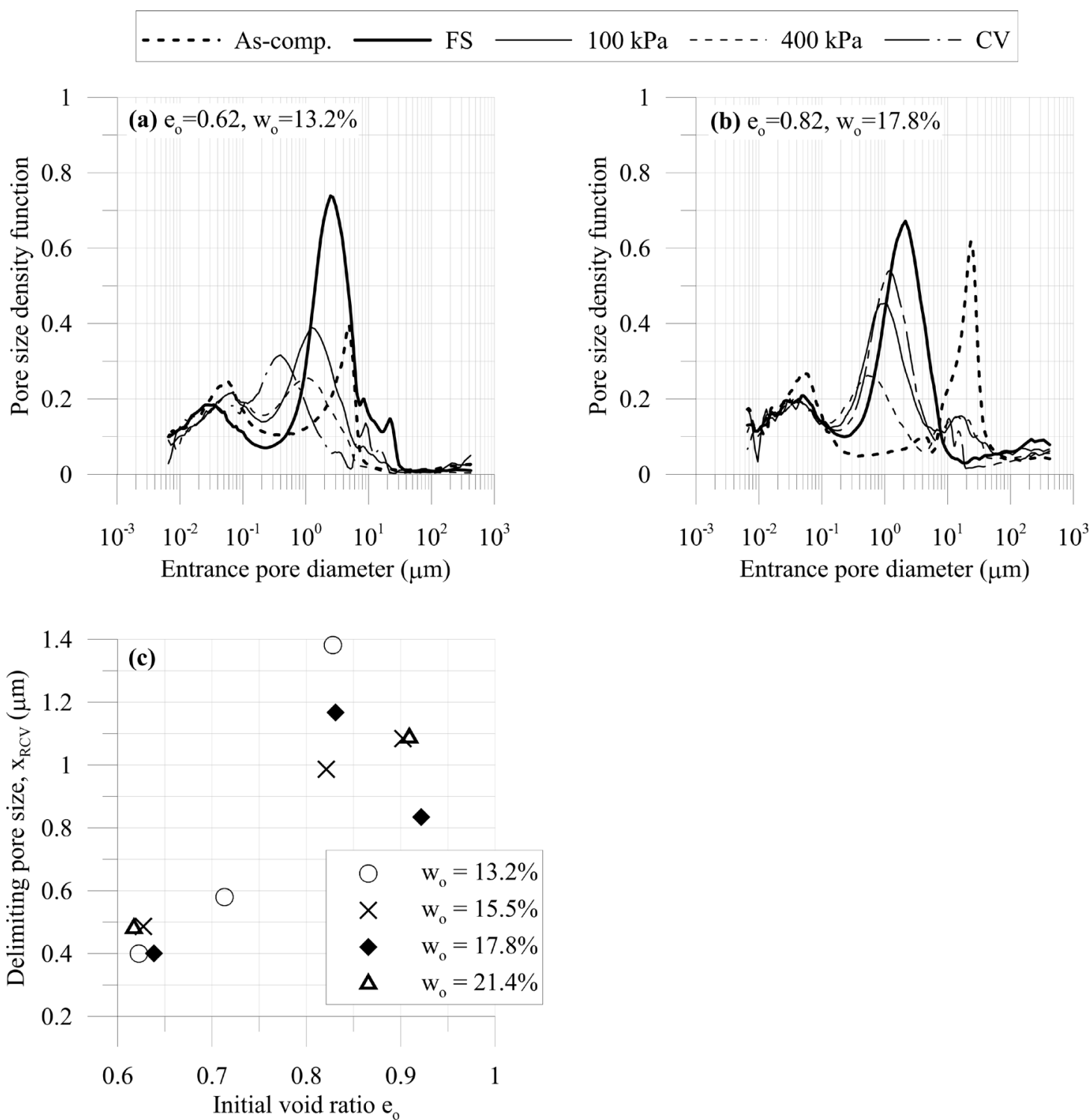

Figure 3 (a) Pore size distribution of compacted Maryland clay samples $\left(\mathrm{e}_{\mathrm{o}}=0.62\right.$, $\mathrm{W}_{\mathrm{o}}=13.2 \%$ ) upon swelling under different boundary conditions. FS: free swelling, CVS: constant vertical stress, CV: constant volume (after Yuan et al., 2016). (b): Pore size distribution of Maryland clay specimen $\left(\mathrm{e}_{\mathrm{o}}=0.82, \mathrm{w}_{\mathrm{o}}=17.8 \%\right)$ after compaction and following swelling under constant volume or under constant vertical stress (after Yuan et al., 2016). (c): Evolution of delimiting pore size determined by the RCV criterion with initial void ratio for compacted Maryland clay samples subjected to constant volume swelling (after Yuan et al., 2016). 
Table 3: Summary of delimiting diameter for four different initial conditions applied to compacted Maryland clay.

\begin{tabular}{|l|l|l|l|l|}
\hline Delimiting diameter for & \multicolumn{2}{|l|}{$w_{o}=13.2 \%$} & $w_{o}=17.8 \%$ & \\
\cline { 3 - 5 } compacted Maryland Clay $(\mu \mathrm{m})$. & $e_{o}=0.62$ & $e_{o}=0.82$ & $e_{o}=0.62$ & $e_{o}=0.82$ \\
\hline RCV Criterion & 0.60 & 0.60 & 0.8 & 1.2 \\
\hline RFS Criterion & $2-2.5$ & 1.4 & 1.4 & 2.1 \\
\hline SWRC Criterion & \multicolumn{3}{|l}{0.8} \\
\hline
\end{tabular}

\section{4- Discussion}

172 The idea behind a fixed criteria is laudable as it provides a value "once for all", that can then 173 be applied to other PSDs (Romero et al., 2011). However, this idea is somewhat defeated by 174 the influence of initial conditions and boundary conditions. The SWRC criterion provides a 175 single delimiting diameter but accurately measuring retention curves at constant void ratio can 176 be time consuming. Another issue arises with fixed criteria if the dominat peaks shift significantly upon swelling (see Figures 2 and 3) and drying (see Figure 4).

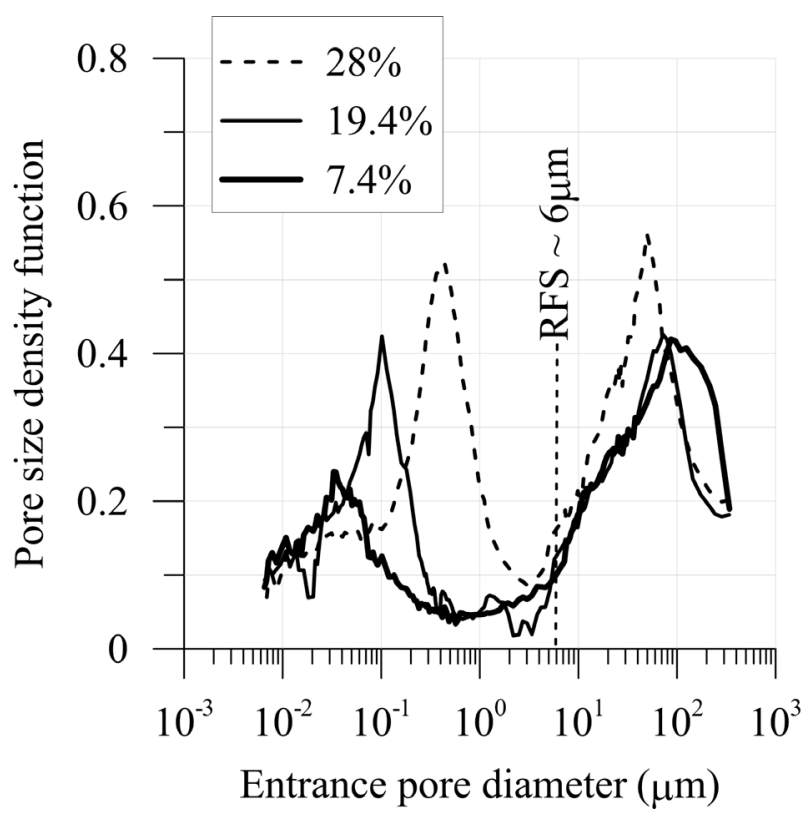

Figure 4: evolution of pore size distribution of compacted Maryland clay undergoing airdrying from initial conditions of $\mathrm{w}_{\mathrm{o}}=28 \%, \mathrm{e}_{\mathrm{o}}=1.27$ (after Burton et al., 2015). The RFS value of 6 micrometer was estimated from swell test C10 in Burton et al. (2015). 


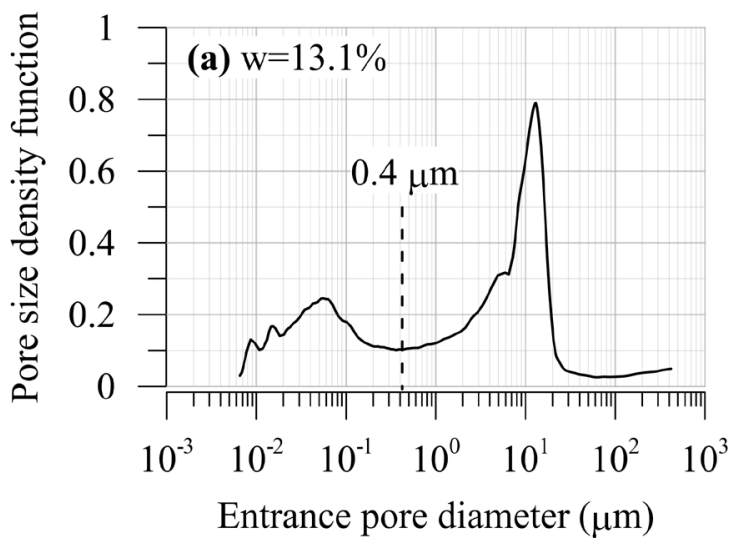
Yuan et al., 2020).

In Figure 4, the RFS delimiting diameter clearly encroaches on the macropores, which will result in an overestimation of the micro void ratio $\mathrm{e}_{\mathrm{m}}$. In contrast, using a moving boundary (e.g. VALL criterion) seems more adequate to track microstructural changes.

It may be useful for researchers to estimate how much the micro/macro boundary may shift upon wetting and drying in order to interpret microstructural data more easily and more adequately. It was found, for Maryland clay, that the extent of pore size changes upon wetting and drying can be approximated from the microstructural data of the material compacted dry and wet of its optimum. Indeed, Figure 5 shows VALL delimiting diameters of 0.4 and 3.5 micrometer for $13.1 \%$ and $32 \%$ water content, respectively, to be compared to $0.4 \mu \mathrm{m}$ (air drying to $\mathrm{w}=7.5 \%$, Figure 4 ) and $2.5 \mu \mathrm{m}$ (RCV criterion, Figure 3 ). Note that the position of the lowest point in Figure 5 does not depend on the void ratio achieved by compaction and is only marginally affected by the water content at high and low values of water content (see

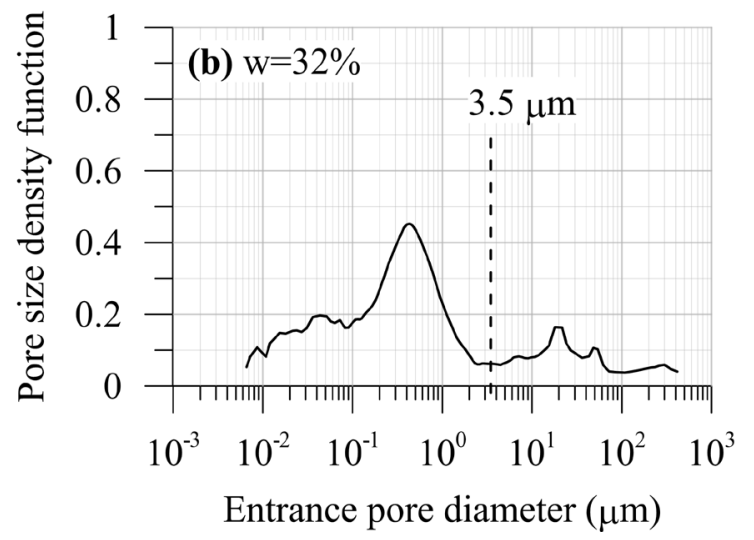

Figure 5: Pore size distribution of Maryland clay compacted to a void ratio of 0.9 with a water content of $13.1 \%$ (a) and $32 \%$ (b). The value associated with the lowest point of the valley between the pore populations is reported on each distribution. Data from Yuan et al. (2020).

194 For clear bimodal distributions, the adequacy of a criterion to separate micropores and macropores can easily be assessed. The criterion is used for consistency in defining the delimiting diameter. For distributions that are not clearly bimodal, it is advised to track microstructural changes with loading via successive PSDs (as per Figure 2) to help in defining 
an adequate delimiting diameter. Special attention should be paid to cases where pore populations tend to merge, either partially or completely.

200 If pore populations can not be identified, one can question the appropriateness of trying to define micropores and macropores, especially if the results are to be interpreted in terms of inter-aggregates and intra-aggregates porosity.

203 Finally, it is suggested to account for the physical response of compacted soils when deciding on a delimiting diameter. For example, Yuan and co-workers used a value of $1 \mu \mathrm{m}$ for Maryland clay, which allows capturing:

206

- The decrease of macro pores upon compaction (Delage and Graham, 1995; Lloret and Villar, 2007) (Figure 6a)

208

- The collapse of macro pores upon wetting (Figure 6b).

- Aggregate swelling under hydration for different values of vertical stress (Figure 6c). Yuan et al. (2016) quantified the void ratio associated to the micro pores before swelling $\left(e_{m o}\right)$ and after a swelling phase under a constant normal stress $\left(e_{m}\right)$. A negative change in micro void ratio $\left(e_{m}-e_{m o}\right)$ reflects shrinkage of aggregates upon hydration, which is not possible and is a reflection of an inadequate delimiting diameter.

- $\quad$ The merging point of retention curves, as per SWRC criterion (approximately).

215 However, a $1 \mu \mathrm{m}$ delimiting diameter is not ideal at the end of free swelling, when pore 216 populations merge with a peak around $2.5 \mu \mathrm{m}$. For the fully swollen states, regardless of 217 boundary conditions, it is recommended to align the delimiting diameter with the merged peak 218 (similar to RFS or RCV criteria). 


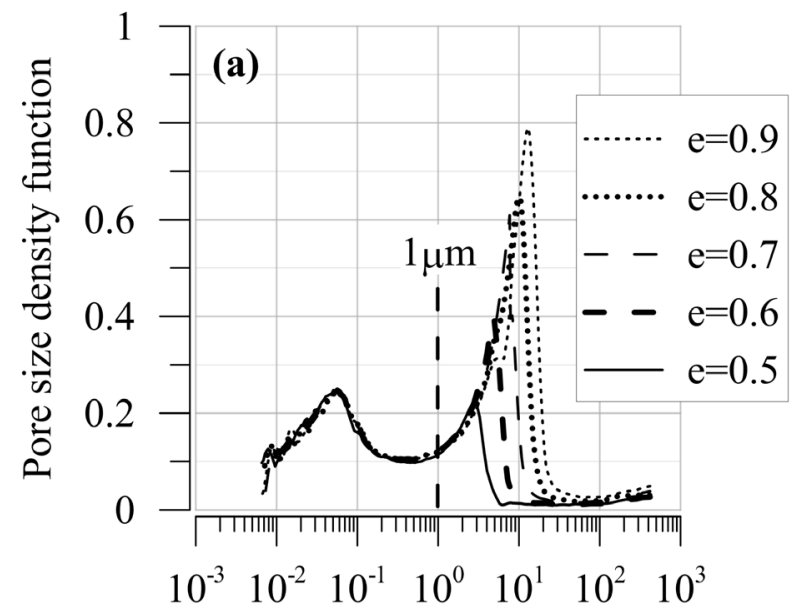

Entrance pore diameter $(\mu \mathrm{m})$

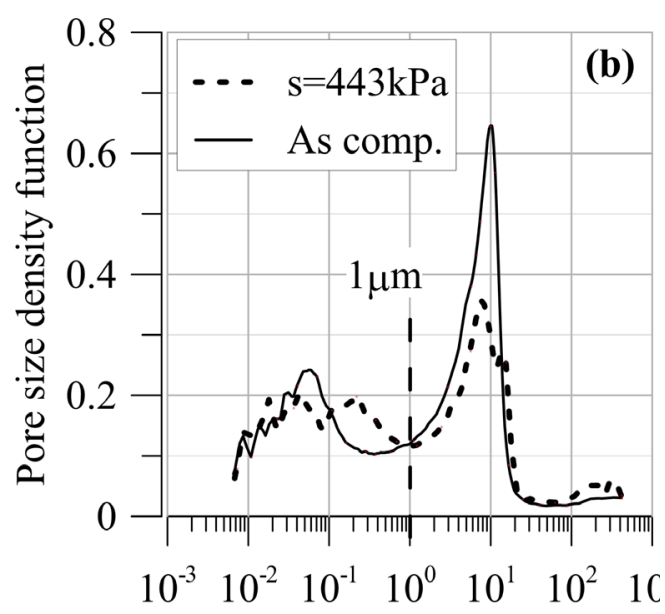

Entrance pore diameter $(\mu \mathrm{m})$

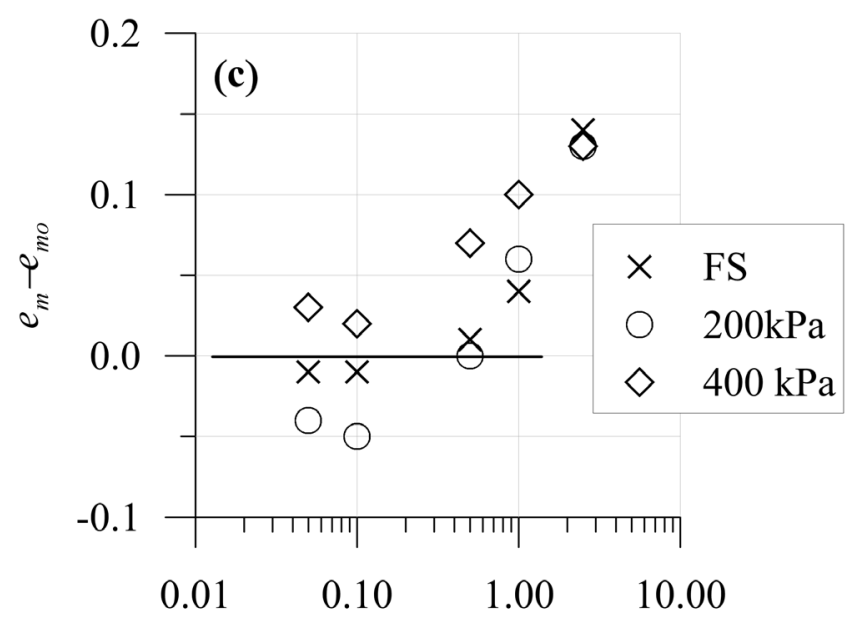

Delimiting diameter $D D(\mu \mathrm{m})$

Figure 6: (a): Pore size distribution of Maryland clay compacted at a water content of $13.2 \%$ and at five different void ratios. Data from Yuan et al. (2020). (b): Pore size distribution of Maryland after compaction (initial suction of $6300 \mathrm{kPa}$, initial void ratio of 0.8 ) and after incremental swelling (to a suction of $473 \mathrm{kPa}$ ) leading to collapse. Data from Yuan et al. (2020). (c) Change in micro void ratio after free swelling and swelling under $200 \mathrm{kPa}$ and $400 \mathrm{kPa}$, for different values of delimiting diameter. Data after Yuan et al. (2016). $e_{m}$ is the micro void ratio at the end of swelling, $e_{m o}$ is the micro void ratio after compaction, prior swelling.

222 Several criteria have been proposed to distinguish micropores and macropores in bimodal pore 223 size distributions of compacted clayey soils. Five of the most commonly used criteria were 
applied to microstructural data obtained on compacted Maryland clay undergoing swelling and drying. Three of these criteria (RFS, RCV, SWRC) return a fixed value of delimiting factor while the other two (VALL, CNC) return a moving boundary. Different criteria were found to return very different values of delimiting diameters. The criterion based on intrusion and extrusion curves significantly underestimates the micro/macro boundary. The analysis of microstructural data also showed a strong dependence of the RFS and RCV criteria to initial and boundary conditions, which defeats the idea of providing a fixed boundary. For Maryland clay, the position of dominant peaks shift significantly under wetting and drying, which fixed value criteria do not adequately capture. It is proposed to analyse successive PSDs to better track microstructural changes and define an adequate delimiting diameter. This is particularly relevant when pore populations merge upon swelling. Finally, it is advised to verify that the computed values of micro void ratio is compatible with known response of compacted clayey soils.

\section{Acknowledgements}

The authors would like to express their gratitude to the Australian Research Council (ARC) for the financial support (ARC DP110103304).

\section{References}

Agus S. S., Schanz T. 2005. Effect of shrinking and swelling on microstructures and fabric of a compacted bentonite-sand mixture. Proceedings of the international conference on problematic soils, Cyprus, 2, 543-550.

Ahmed S., Lovell C.W., Diamond S. 1974. Pore sizes and strength of compacted clay. J Geotech Eng Div ASCE, 100(4):407-425

Alonso E. E., Vaunat J., Gens A. 1999. Modelling the mechanical behaviour of expansive clays. Engineering Geology, 54 (1): 173-183.

Burton G.J., Pineda J.A., Sheng D., and Airey D. 2015. Microstructural changes of an undisturbed, reconstituted and compacted high plasticity clay subjected to wetting and drying. Engineering Geology, 193: 363-373.

Casini F., Vaunat J., Romero E., Desideri A. 2012. Consequences on water retention properties of double-porosity features in a compacted silt. Acta Geotechnica, 7(2): 139150. 
Casini F., Vaunat J., Romero E. 2013. A microstructural model on the link between change in pore size distribution and wetting induced deformation in a compacted silt. In Poromechanics V proceedings of the 5th Biot conference on Poromechanics, 1309-1313.

Delage P., Lefebvre G. 1984. Study of the structure of a sensitive Champlain clay and of its evolution during consolidation. Canadian Geotechnical Journal, 21(1): 21-35.

Delage P., Graham J. 1995. The mechanical behaviour of unsaturated soils In Proceedings of 1st International Conference on Unsaturated Soils, Paris, vol 3: 1223-1256

Delage P., Pellerin F.M., 1984. Influence de la lyophilisation sur la structure d'une argile sensible du Quebec. Clay Minerals. 19(2): 151-160.

Delage P., Audiguier M., Cui Y., Howatt M.D. 1996. Microstructure of a compacted silt. Canadian Geotechnical Journal, 33(1):150-158

Delage P., Marcial D., Cui Y., and Ruiz X. 2006. Ageing effects in a compacted bentonite: a microstructure approach. Géotechnique, 56(5): 291-304.

Della Vecchia G., Jommi C., Romero E. 2013. A fully coupled elastic-plastic hydromechanical model for compacted soils accounting for clay activity. International Journal for Numerical and Analytical Methods in Geomechanics, 37(5): 503-535.

Diamond, S. 1970. Pore Size Distributions in Clays. Clays and Clay Minerals, 18(1): 7-23.

Koliji A., Laloui L., Cuisinier O., Vulliet L. 2006. Suction induced effects on the fabric of a structured soil. Transport in Porous Media, 64(2):261-278

Li X., Zhang, L. M. (2009). Characterization of dual structure pore size distribution of soil. Canadian Geotechnical Journal, 46(2):129-141.

Liu X., Buzzi O., Yuan S., Mendes J., Fityus S. 2016. Multi-scale characterization of the retention and shrinkage behaviour of four Australian clayey soils. Canadian Geotechnical Journal, 53(5): 854-870.

Lloret A., Villar M.V. 2007. Advances on the knowledge of the thermo-hydro-mechanical behaviour of heavily compacted "FEBEX" bentonite. Physics and Chemistry of the Earth, Parts A/B/C, 32(8-14): 701-715.

Masin D. 2016. Development of a coupled thermo-hydro-mechanical double structure model for expansive soils, 3rd European Conference on Unsaturated Soils, E-UNSAT 2016, Article number 17002.

Monroy R., Zdravkovic L., Ridley A. 2010. Evolution of microstructure in compacted London Clay during wetting and loading. Géotechnique, 60(2): 105-119.

Romero E., Gens A., Lloret A. 1999. Water permeability, water retention and microstructure of unsaturated Boom clay. Engineering Geology, 54(1-2):117-127 
Romero E., Simms P.H. 2009. Microstructure investigation in unsaturated soils: A review with special attention to contribution of mercury intrusion porosimetry and environmental scanning electron microscopy. In Laboratory and Field Testing of Unsaturated Soils. Springer Netherlands, 93-115.

Romero E., Della Vecchia G., Jommi C. 2011. An insight into the water retention properties of compacted clayey soils. Géotechnique, 61(4): 313-328.

Romero E. 2013. A microstructural insight into compacted clayey soils and their hydraulic properties. Engineering Geology, 165: 3-19.

Sánchez M., Gens A., Guimaráes L., Olivella S. 2005. A double structure generalized plasticity model for expansive materials. International Journal for Numerical and Analytical Methods in Geomechanics, 29(8): 751-787.

Simms P.H., Yanful E.K. 2001. Measurement and estimation of pore shrinkage and pore distribution in a clayey till during soil-water characteristic curve tests. Canadian Geotechnical Journal, 38(4): 741-754.

Simms P.H., Yanful E.K. 2002. Predicting soil-water characteristic curves of compacted plastic soils from measured pore-size distributions. Géotechnique, 52(4): 269-278.

Simms P.H., Yanful E.K. 2005. A pore-network model for hydromechanical coupling in unsaturated compacted clayey soils. Canadian Geotechnical Journal, 42(2):499-514

Sridharan A., Altschaeffl A.G., Diamond S. 1971. Pore size distribution studies. Journal of Soil Mechanics and Foundations Division, 97(5): 771-787.

Thom, R., Sivakumar, R., Sivakumar, V., Murray, E.J., and Mackinnon, P. 2007. Pore size distribution of unsaturated compacted kaolin: the initial states and final states following saturation. Géotechnique, 57(5): 469-474.

Yong R.N. 1999. Overview of modeling of clay microstructure and interactions for prediction of waste isolation barrier performance. Engineering Geology, 54(1-2): 83-91.

Yuan S., Liu X., Buzzi O. 2018. Technical aspects of mercury intrusion porosimetry for clays. Environmental Geotechnics, https://doi.org/10.1680/jenge.16.00039.

Yuan S., Liu X., Buzzi O. 2019b. Effects of soil structure on the permeability of saturated Maryland clay. Géotechnique, 69(1), 72-78.

Yuan S., Liu X., Buzzi O. 2020. A microstructural perspective into soil collapse. Geotechnique, https://doi.org/10.1680/jgeot.18.P.256.

Yuan S., Buzzi O., Liu X., Vaunat J. 2019a. Swelling behaviour of Maryland clay under different boundary conditions. Géotechnique, 69(6), 514-525.

Yuan S., Liu X., Sloan S.W., Buzzi O.P. 2016. Multi-scale characterization of swelling behaviour of compacted Maryland clay. Acta Geotechnica, 11(4): 789-804. 

Porosimetry Tests, in: Soil Specimen Preparation for Laboratory Testing, ASTM STP 599. American Society for Testing and Materials, 202-215. 